\section{Prevalência e fatores associados à percepção de ocorrência de corrimento vaginal patológico entre gestantes}

\author{
Prevalence of self-reported vaginal discharge \\ and associated factors in pregnant women
}

\author{
1 Divisão de População \& \\ Saúde, Universidade Federal \\ do Rio Grande, Rio Grande, \\ Brasil. \\ 2 Pós-graduação em \\ Epidemiologia, Universidade \\ Federal de Pelotas, Pelotas, \\ Brasil. \\ 3 Hospital Universitário, \\ Universidade Federal do Rio \\ Grande, Rio Grande, Brasil. \\ Correspondência \\ J. A. Cesar \\ Divisão de População \& \\ Saúde, Universidade Federal \\ do Rio Grande. \\ Rua General Osório $s / n$, \\ Campus Saúde, Rio Grande, RS \\ 96200-400, Brasil. \\ jacesar@terra.com.br
}

\begin{abstract}
This study aims to determine the prevalence self-reported abnormal vaginal discharge and to identify associated risk factors in pregnant women in the municipality of Rio Grande, Rio Grande do Sul State, Brazil. A standardized questionnaire was applied to all pregnant women admitted for delivery in local maternity hospitals. The chi-square test was used to compare proportions and Poisson regression was applied using multivariate analysis. Prevalence of vaginal discharge was 40\%. Adjusted analysis showed the following prevalence ratios for vaginal discharge: 1.6 (1.4-1.8) for adolescents; 1.3 (1.1-1.6) for 8 years of schooling or less; 1.3 (1.1-1.5) for alcohol consumption; 2.0 (1.8-2.2) for vaginal discharge in the previous pregnancy; 1.4 (1.3-1.6) for urinary tract infection in the current pregnancy; and 0.8 (0.7-0.9) for history of prematurity. Local health services should target adolescent women, those with low schooling or low family income, and those with a history of vaginal discharge in the previous pregnancy or urinary tract infection in the current pregnancy.
\end{abstract}

Vaginal Discharge; Vaginitis; Pregnant Women
Juraci A. Cesar 1,2

Raúl A. Mendoza-Sassi 1

David A. González-Chica 2

Eduardo H. M. Menezes 3

Günther Brink 3

Marcela Pohlmann 3

Tania M. V. Fonseca ${ }^{3}$

\section{Introdução}

Corrimento vaginal é uma das afecções mais comuns na idade fértil e um dos principais motivos de consulta médica em atenção primária em saúde 1. Acomete cerca de um terço de todas as mulheres e praticamente metade das gestantes 1,2,3. O corrimento vaginal patológico caracteriza-se pela presença de ardência e/ou prurido vulvovaginal, dispareunia, disúria e eliminação de secreções de diferentes colorações e com odor fétido 1,2. Este tipo de corrimento decorre, em geral, de agentes associados a doenças sexualmente transmitidas (DST) 4 .

Diversos fatores de risco já foram identificados, dentre eles idade inferior a 20 anos, cor da pele preta, baixo poder aquisitivo, união conjugal não estável, múltiplos parceiros sexuais, manter relação sexual sem uso de preservativos 5,6,7,8 uso de dispositivo intra-uterino, ocorrência de hiperglicemia e/ou infecção urinária na gestação atual, parto prematuro prévio $4,7,8$, tabagismo e desordens psicológicas como estresse, depressão e ansiedade 9,10 .

As complicações mais comuns conseqüentes ao corrimento vaginal patológico são infecção urinária, prematuridade, baixo peso ao nascer, corioamnionite, endometrite puerperal e infecção da ferida operatória pós-cesárea 4,7,11,12. Este tipo de corrimento aparece ainda associado a risco aumentado de infecção pelo vírus da imu- 
nodeficiência humana (HIV), sobretudo se em presença de DST com úlceras genitais 2,3,12.

Destas infecções, as que resultam em prematuridade e baixo peso ao nascer são as que apresentam maiores (e mais graves) repercussões sobre a saúde infantil 4,5,6,7. Estas crianças apresentam probabilidade substancialmente maior que os demais de adoecer e morrer no primeiro ano de vida e de apresentarem, já no inicio da vida adulta, doenças crônico-degenerativas 13 .

Este estudo teve por objetivo medir a prevalência e identificar fatores associados à percepção de ocorrência de corrimento vaginal patológico entre gestantes residentes no Município de Rio Grande, Rio Grande do Sul, Brasil, no ano de 2007.

\section{Metodologia}

Rio Grande possui cerca de 200 mil habitantes e está localizado na metade sul do Rio Grande do Sul, distante $300 \mathrm{~km}$ de Porto Alegre, a capital do estado. Sua economia é bem diversificada, com predomínio da atividade portuária, da indústria petroquímica, de fertilizantes e de pescados. $\mathrm{O}$ comércio e a atividade agrícola são, também, importantes atividades econômicas. O sistema de saúde é constituído por dois hospitais gerais, com 715 leitos destinados ao Sistema Único de Saúde (SUS), bem como cinco ambulatórios especializados e 32 unidades básicas de saúde.

Foram incluídas neste estudo todas as mães residentes no Município de Rio Grande que tiveram filho entre 1o de janeiro e 31 de dezembro de 2007 no Hospital Universitário Dr. Miguel Riet Correa Jr. e na Santa Casa de Misericórdia de Rio Grande, os dois únicos hospitais da cidade. Nas duas maternidades destes hospitais, segundo dados do Sistema de Informações sobre Mortalidade (SIM) e do Sistema de Informação sobre Nascidos Vivos (SINASC), nascem pelo menos 99\% de todas as crianças do município. O delineamento utilizado foi do tipo transversal, com as mães sendo entrevistadas uma única vez em alguma dessas maternidades.

Entrevistadores previamente treinados visitavam diariamente estas maternidades e aplicavam questionário único pré-codificado buscando informações sobre local de residência da família, características demográficas e história reprodutiva materna; nível sócio-econômico, posse de eletrodomésticos e condições de habitação e saneamento da família, assistência recebida durante a gestação e o parto e intercorrências durante a gestação.

Embora a maioria das variáveis seja autoexplicativa, algumas delas necessitam de esclarecimentos adicionais, a saber:
- Cor da pele: classificada pelo entrevistador em branca, parda/morena e preta;

- Renda familiar: valor recebido por todos os moradores do domicilio no mês imediatamente anterior à entrevista;

- Índice de bens: incluiu aspirador de pó, máquina de lavar roupa, DVD, geladeira, freezer, forno microondas, computador, telefone fixo, rádio, televisão, automóvel, ar condicionado e empregada doméstica fixa. Nesta variável também foram incluídas escolaridade da mãe e renda familiar. Dos distintos componentes gerados, o primeiro deles foi usado para criar um escore contínuo em que todas as variáveis incluídas contribuíram de forma direta. Este componente teve um eigenvalue de 5,18, explicando $32 \%$ da variabilidade total 14. Esta variável foi posteriormente dividida em tercis para as distintas análises realizadas;

- Tabagismo materno: se fumou pelo menos uma vez nos seis meses anteriores a gravidez;

- Consumo de álcool: se costumava tomar bebida alcoólica durante a gravidez;

- Índice de massa corporal (IMC): peso da gestante dividido pela altura ao quadrado;

- Ganho de peso durante a gestação: diferença entre o peso referido no início da gravidez e o peso obtido imediatamente antes do parto; e

- Percepção de corrimento vaginal patológico: relato da ocorrência de corrimento vaginal associado à pelo menos um dos seguintes sintomas: prurido, disúria, dispareunia, odor e coloração que não branco 2 .

Dez entrevistadores foram treinados durante cinco dias consecutivos. Este treinamento consistiu de leitura do questionário e do manual de instruções e aplicação do questionário em duplas entre si e perante todo o grupo de entrevistadores. Destes, oito eram acadêmicas do Curso de Medicina da Universidade Federal do Rio Grande (FURG) e as outras eram graduadas em serviço social com ampla experiência neste tipo de estudo.

O estudo piloto foi realizado nas duas maternidades da cidade, antes do início da coleta definitiva de dados e tinha por objetivo testar o questionário a ser utilizado bem como o enunciado de cada questão. Nesta etapa, cada um dos treinandos aplicou pelo menos quatro questionários completos. Em seguida foram sanadas todas as dúvidas, realizadas as correções no questionário e a versão final impressa. Todos os instrumentos utilizados no estudo foram acompanhados de um manual com instruções detalhadas de preenchimento.

Nos dias úteis, a coleta de dados foi feita pelas duas entrevistadoras, enquanto nos finais de semana e durante feriados, as entrevistas eram 
realizadas pelos bolsistas, todos acadêmicos do Curso de Medicina da FURG.

Ao final de cada dia de trabalho, o entrevistador codificava os questionários por ele aplicados e, na mesma semana, os entregava na sede do estudo onde as questões abertas eram codificadas, os questionários integralmente revisados e entregues à digitação. Neste local, eram duplamente digitados por diferentes profissionais, sendo que a segunda digitação era feita na ordem inversa da primeira. Ao término de cada lote, estas digitações eram comparadas e os erros listados e corrigidos. O passo seguinte envolveu a verificação de consistência dos dados para cada bloco de variáveis. Respostas incongruentes eram checadas de posse do questionário e, quando necessário, o mesmo era devolvido para o supervisor da coleta de dados a fim de elucidar o problema com a entrevistadora responsável. Estas etapas foram realizadas através do programa Epi Info 6.4 (Centers for Disease Control and Prevention, Atlanta, Estados Unidos). Ao final desta etapa, os dados eram acumulados em um banco para colocação de rótulos, análise de consistência e criação das variáveis derivadas. Todas estas etapas bem como a análise multivariada descrita a seguir foram realizadas utilizando-se do pacote estatístico Stata versão 9.2 (Stata Corp., College Station, Estados Unidos).

A análise multivariada foi realizada obedecendo à modelo hierárquico previamente definido. Neste modelo, algumas variáveis eram consideradas sobredeterminantes em relação às demais. As variáveis do primeiro nível poderiam atuar diretamente sobre o desfecho, no caso percepção de corrimento vaginal patológico durante a gestação, ou, através das variáveis localizadas nos demais níveis, atuarem de forma indireta, sobre a doença em questão. A Tabela 1 apresenta os diferentes níveis deste modelo bem como as variáveis incluídas em cada nível 15 .

A significância estatística de cada variável no modelo foi avaliada através do teste de Wald 16. Inicialmente, cada bloco de variáveis de um determinado nível foi incluído na análise, mantendo-se no modelo todas aquelas variáveis com valor de $\mathrm{p} \leq 0,20$. Neste modelo, as variáveis, situadas em um nível hierarquicamente superior ao da variável em questão, eram consideradas como potenciais confundidores na relação com o desfecho, enquanto as variáveis situadas em níveis inferiores eram consideradas como potenciais mediadores da associação. As variáveis, selecionadas em um determinado nível, permaneciam no modelo sendo consideradas como potenciais fatores de risco para o desfecho em questão, mesmo que, com a inclusão de variáveis hierarquicamente inferiores, viessem a perder sua significância estatística. Para as comparações entre proporções, utilizou-se teste do qui-quadrado com correção de Yates para tabelas 2x2, enquanto, para a análise multivariada, utilizou-se a regressão de Poisson com controle para efeito de delineamento e ajuste robusto da variância 16

Para o controle de qualidade, foram refeitas $10 \%$ de parte das entrevistas com as mães nas residências utilizando-se questionário padrão resumido. O principal objetivo desta atividade era garantir que as entrevistas tivessem sido realizadas, bem como de comparar as respostas obtidas entre estes questionários-controle e o original aplicado pelo entrevistador.

O protocolo de pesquisa foi submetido e aprovado pelo Comitê de Ética em Pesquisa na Área da Saúde (CEPAS) da FURG. Além disso, garantiram-se a confidencialidade dos dados, a participação voluntária e a possibilidade de deixar o estudo a qualquer momento, sem necessidade de justificativa.

\section{Resultados}

Dentre as 2.558 mães residentes no Município de Rio Grande que deram à luz nas duas maternidades da cidade, foi possível obter informações sobre 2.523 delas. Isto representa uma taxa de resposta de $98,6 \%$. Dentre as 34 gestantes que não participaram do estudo, uma recusou-se e as demais não foram encontradas. Das 2.557 que efetivamente participaram deste estudo, $79 \%$ foram hospitalizadas pelo SUS, $16 \%$ através de convênios e $5 \%$ de forma totalmente particular.

A prevalência de corrimento vaginal entre todas as gestantes estudadas foi de $40 \%$. A Tabela 2 mostra maior prevalência de corrimento vaginal entre gestantes de cor da pele preta (46\%), com idade entre 13 e 19 anos (52\%), que não possuíam marido/companheiro (44\%), com escolaridade entre 5 e 8 anos (46\%), pertencentes ao pior tercil de renda familiar $(45 \%)$, com menor disponibilidade de bens no domicilio (45\%), que não trabalharam durante a gravidez (43\%) e que moravam com três ou mais pessoas no domicílio (42\%). A Tabela 3 mostra maior ocorrência de corrimento vaginal entre gestantes que relataram consumo de álcool durante a gravidez (54\%), que tiveram filhos nascidos mortos previamente (43\%), que referiram corrimento em gestação anterior $(72 \%)$, que não realizaram citopatológico de colo uterino antes desta gestação (42\%) e com IMC inferior a $18,5 \mathrm{~kg} / \mathrm{m}^{2}$. Na Tabela 4 verifica-se maior prevalência de corrimento vaginal entre aqueles que iniciaram o pré-natal no terceiro trimestre de gravidez (50\%), que realizaram de 2 a 5 
Tabela 1

Modelo hierárquico de análise para fatores associados à ocorrência de corrimento vaginal patológico.

\begin{tabular}{|c|c|c|}
\hline Nível & \multicolumn{2}{|c|}{ Variáveis } \\
\hline 1 & Demográficas: cor da pele, idade e estado civil & $\begin{array}{l}\text { Sócio-econômicas: escolaridade materna e trabalho materno, renda } \\
\text { familiar, índice de bens e número de moradores no domicílio }\end{array}$ \\
\hline 2 & $\begin{array}{l}\text { Reprodutivas: paridade e ocorrência de natimortos, } \\
\text { abortos, prematuros e baixo peso prévio }\end{array}$ & $\begin{array}{l}\text { Morbidade prévia: corrimento em gravidez anterior, realização } \\
\text { de citopatológico e índice de massa corporal atual }\end{array}$ \\
\hline 3 & $\begin{array}{l}\text { Assistência à gestação atual: idade de início do pré-natal, } \\
\text { número de consultas e local em que foram realizadas }\end{array}$ & $\begin{array}{l}\text { Morbidade atual: diabetes, infecção do trato urinário } \\
\text { e ganho de peso durante a gestação }\end{array}$ \\
\hline Desfecho & \multicolumn{2}{|c|}{ Percepção de corrimento vaginal patológico entre gestantes } \\
\hline
\end{tabular}

Tabela 2

Análise bruta e ajustada da prevalência de corrimento conforme variáveis sócio-econômicas, demográficas e de moradia. Rio Grande, Rio Grande do Sul, Brasil, 2007

\begin{tabular}{|c|c|c|c|c|}
\hline Variáveis & $\mathrm{n}$ & $\begin{array}{l}\text { Prevalência de } \\
\text { corrimento (\%) }\end{array}$ & $\begin{array}{l}\text { Análise bruta } \\
\text { RP (IC95\%) }\end{array}$ & $\begin{array}{c}\text { Análise ajustada } \\
\text { RP (IC95\%) }\end{array}$ \\
\hline Cor da pele * & & & $p=0,008 * \star$ & $p=0,2 * *$ \\
\hline Branca & 1.760 & 38,5 & 1,00 & 1,00 \\
\hline Parda/Mulata & 462 & 43,5 & $1,13(1,00-1,27)$ & $1,07(0,95-1,20)$ \\
\hline Preta & 301 & 46,5 & $1,21(1,06-1,38)$ & $1,14(0,99-1,30)$ \\
\hline Idade (anos) * & & & $\mathrm{p}<0,001 * \star *$ & $\mathrm{p}<0,001 * * *$ \\
\hline $13-19$ & 515 & $51, \%$ & $1,57(1,37-1,80)$ & $1,53(1,33-1,76)$ \\
\hline $20-24$ & 714 & 43,0 & $1,31(1,14-1,50)$ & $1,29(1,12-1,48)$ \\
\hline $25-29$ & 614 & 36,2 & $1,10(0,95-1,28)$ & $1,10(0,95-1,28)$ \\
\hline$\geq 30$ & 680 & 32,8 & 1,00 & 1,00 \\
\hline Estado civil * & & & $p=0,06$ ** & $p=0,6$ * \\
\hline Sem marido/companheiro & 438 & 44,3 & $1,12(1,00-1,26)$ & $1,04(0,91-1,17)$ \\
\hline Com marido/companheiro & 2.085 & 39,5 & 1,00 & 1,00 \\
\hline Escolaridade (anos) \# & & & $p<0,001 * \star \star$ & $p=0,006 * \star \star$ \\
\hline $0-4$ & 319 & 41,7 & $1,39(1,10-1,76)$ & $1,24(0,97-1,57)$ \\
\hline $5-8$ & 912 & 46,2 & $1,54(1,25-1,90)$ & $1,27(1,02-1,57)$ \\
\hline $9-11$ & 1.055 & 37,3 & $1,24(1,01-1,53)$ & $1,09(0,89-1,35)$ \\
\hline 12 ou mais & 237 & 30,0 & 1,00 & 1,00 \\
\hline Renda familiar (R\$) \# & & & $\mathrm{p}<0,001 * \star *$ & $\mathrm{p}=0,009 * \star \star$ \\
\hline Tercil inferior & 848 & 45,4 & $1,28(1,14-1,44)$ & $1,16(1,02-1,30)$ \\
\hline Tercil médio & 838 & 40,2 & $1,14(1,01-1,29)$ & $1,09(0,96-1,23)$ \\
\hline Tercil superior & 837 & 35,4 & 1,00 & 1,00 \\
\hline Índice de bens * & & & $p<0,001 * * *$ & $p=0,006 * \star \star$ \\
\hline Tercil inferior & 844 & 44,9 & $1,33(1,18-1,50)$ & $1,20(1,05-1,36)$ \\
\hline Tercil médio & 840 & 42,4 & $1,26(1,11-1,42)$ & $1,16(1,03-1,32)$ \\
\hline Tercil superior & 837 & 33,7 & 1,00 & 1,00 \\
\hline Trabalhou durante gravidez * & & & $p=0,002 * *$ & $\mathrm{p}=0,6 * \star$ \\
\hline Não & 1.580 & 42,8 & $1,18(1,07-1,31)$ & $1,03(0,91-1,17)$ \\
\hline Sim & 943 & 36,3 & 1,00 & 1,00 \\
\hline
\end{tabular}

(continua) 
Tabela 2 (continuação)

\begin{tabular}{|c|c|c|c|c|}
\hline Variáveis & $\mathrm{n}$ & $\begin{array}{l}\text { Prevalência de } \\
\text { corrimento (\%) }\end{array}$ & $\begin{array}{l}\text { Análise bruta } \\
\text { RP (IC95\%) }\end{array}$ & $\begin{array}{c}\text { Análise ajustada } \\
\text { RP (IC95\%) }\end{array}$ \\
\hline Moradores no domicílio * & & & $p=0,05 * \star \star$ & $p=0,05 \star \star \star$ \\
\hline $1-2$ & 741 & 37,1 & 1,00 & 1,00 \\
\hline $3-4$ & 1.158 & 41,5 & $1,12(0,99-1,25)$ & $1,17(1,04-1,31)$ \\
\hline 5 ou mais & 624 & 42,2 & $1,14(1,00-1,30)$ & $1,13(1,00-1,29)$ \\
\hline
\end{tabular}

* Variáveis conservadas no modelo quando o valor de $\mathrm{p}$ foi $\leq 0,20$ na análise ajustada;

** Teste de Wald de heterogeneidade;

*** Teste de Wald de tendência;

\# Ajustado para outras variáveis do primeiro nível com valor de $p \leq 0,20$, com exceção do índice de bens.

Tabela 3

Análise bruta e ajustada da prevalência de corrimento conforme hábitos maternos, antecedentes reprodutivos e índice de massa corporal (IMC) materno prégestacional. Rio Grande, Rio Grande do Sul, Brasil, 2007.

\begin{tabular}{|c|c|c|c|c|}
\hline Variáveis & $\mathbf{n}$ & $\begin{array}{l}\text { Prevalência de } \\
\text { corrimento (\%) }\end{array}$ & $\begin{array}{l}\text { Análise bruta } \\
\text { RP (IC95\%) }\end{array}$ & $\begin{array}{c}\text { Análise ajustada *,** } \\
\text { RP (IC95\%) }\end{array}$ \\
\hline Fumo materno & & & $p=0,5^{\star \star \star}$ & $p=0,07 \star \star \star$ \\
\hline Não & 1.817 & 40,7 & 1,00 & 1,00 \\
\hline Sim & 706 & 39,4 & $0,97(0,87-1,08)$ & $0,90(0,81-1,01)$ \\
\hline Consumo de álcool materno & & & $p=0,002 * \star \star$ & $p=0,02 * \star \star$ \\
\hline Não & 2.427 & 39,8 & 1,00 & 1,00 \\
\hline Sim & 96 & 54,2 & $1,36(1,12-1,65)$ & $1,27(1,04-1,54)$ \\
\hline Paridade & & & $p=0,6 \#$ & $p=1,0 \#$ \\
\hline 0 & 997 & 40,8 & 1,00 & 1,00 \\
\hline $1-2$ & 871 & 40,3 & $0,99(0,88-1,10)$ & $0,91(0,77-1,07)$ \\
\hline$\geq 3$ & 655 & 39,7 & $0,97(0,86-1,10)$ & $0,99(0,81-1,21)$ \\
\hline Abortos prévios & & & $p=0,9 * \star \star$ & $p=0,2 * \star \star$ \\
\hline Não & 2.039 & 40,3 & 1,00 & 1,00 \\
\hline Sim & 484 & 40,5 & $1,00(0,89-1,13)$ & $1,09(0,96-1,23)$ \\
\hline Natimortos prévios & & & $\mathrm{p}=0,6 \star \star \star *$ & $\mathrm{p}=1,0 * \star \star$ \\
\hline Não & 2.435 & 40,3 & 1,00 & 1,00 \\
\hline Sim & 88 & 43,2 & $1,07(0,84-1,37)$ & $1,01(0,74-1,37)$ \\
\hline Prematuros prévios & & & $p=0,06 * \star \star$ & $p=0,009 * \star \star$ \\
\hline Não & 2.234 & 41,1 & 1,00 & 1,00 \\
\hline Sim & 289 & 35,0 & $0,85(0,72-1,00)$ & $0,80(0,68-0,95)$ \\
\hline Baixo peso ao nascer prévio & & & $p=0,3^{\star \star \star}$ &  \\
\hline Não & 2.242 & 40,7 & 1,00 & 1,00 \\
\hline Sim & 281 & 37,4 & $0,92(0,78-1,08)$ & $1,02(0,81-1,26)$ \\
\hline Corrimento gestação prévia & & & $p<0,001 * \star \star$ & $p<0,001 * \star *$ \\
\hline Não & 2.252 & 36,8 & 1,00 & 1,00 \\
\hline Sim & 248 & 71,8 & $1,95(1,78-2,15)$ & $1,94(1,75-2,16)$ \\
\hline $\begin{array}{l}\text { Exame citopatológico de colo } \\
\text { uterino antes da gestação }\end{array}$ & & & $\mathrm{p}<0,001 * \star \star$ & $p=0,2 * \star \star$ \\
\hline Não & 1.935 & 42,4 & $1,26(1,11-1,43)$ & $1,09(0,96-1,24)$ \\
\hline Sim & 588 & 33,7 & 1,00 & 1,00 \\
\hline
\end{tabular}

(continua) 
Tabela 3 (continuação)

\begin{tabular}{|c|c|c|c|c|}
\hline Variáveis & $\mathbf{n}$ & $\begin{array}{l}\text { Prevalência de } \\
\text { corrimento (\%) }\end{array}$ & $\begin{array}{l}\text { Análise bruta } \\
\text { RP (IC95\%) }\end{array}$ & $\begin{array}{c}\text { Análise ajustada *,** } \\
\text { RP (IC95\%) }\end{array}$ \\
\hline IMC pré-gestacional (kg/m²) & & & $p=0,5^{\star \star \star}$ & $p=0,5^{\star \star \star}$ \\
\hline$<18,5$ & 148 & 43,9 & 1,00 & 1,00 \\
\hline $18,5-24,9$ & 1.233 & 41,8 & $0,95(0,78-1,15)$ & $1,09(0,90-1,32)$ \\
\hline $25,0-29,9$ & 425 & 38,1 & $0,87(0,70-1,08)$ & $1,01(0,81-1,26)$ \\
\hline$\geq 30$ & 195 & 39,5 & $0,90(0,70-1,16)$ & $1,13(0,88-1,45)$ \\
\hline
\end{tabular}

* Ajustado para variáveis do primeiro nível: cor da pele, idade materna, índice de bens e número de moradores no domicílio;

** Variáveis conservadas no modelo quando o valor de $p$ foi $\leq 0,20$ na análise ajustada;

*** Teste de Wald de heterogeneidade;

\# Teste de Wald de tendência.

Tabela 4

Análise bruta e ajustada da prevalência de corrimento conforme características da gestação atual. Rio Grande, Rio Grande do Sul, Brasil, 2007.

\begin{tabular}{|c|c|c|c|c|}
\hline Variáveis & $\mathbf{n}$ & Prevalência de corrimento (\%) & $\begin{array}{l}\text { Análise bruta } \\
\text { RP (IC95\%) }\end{array}$ & $\begin{array}{c}\text { Análise ajustada *,** } \\
\text { RP (IC95\%) }\end{array}$ \\
\hline Trimestre de Início do pré-natal & & & $p=0,1 * \star *$ & $p=0,6 * \star \star$ \\
\hline Primeiro & 1.768 & 40,1 & 1,00 & 1,00 \\
\hline Segundo & 577 & 42,3 & $1,06(0,94-1,18)$ & $0,94(0,84-1,06)$ \\
\hline Terceiro & 60 & 50,0 & $1,25(0,96-1,62)$ & $1,11(0,85-1,46)$ \\
\hline Número de consultas de pré-natal & & & $p=0,004 \#$ & $p=1,0 \#$ \\
\hline $0-1$ & 140 & 30,0 & 1,00 & 1,00 \\
\hline $2-5$ & 552 & 44,2 & $1,47(1,12-1,93)$ & $1,02(0,63-1,65)$ \\
\hline $6-9$ & 1.158 & 42,1 & $1,40(1,08-1,82)$ & $1,01(0,62-1,63)$ \\
\hline$\geq 10$ & 636 & 36,6 & $1,22(0,93-1,60)$ & $1,04(0,63-1,70)$ \\
\hline Local de realização do pré-natal & & & $\mathrm{p}<0,001 \#$ & $p=0,2 \#$ \\
\hline Posto de saúde & 992 & 45,1 & 1,00 & 1,00 \\
\hline Ambulatório & 484 & 45,5 & $1,00(0,90-1,14)$ & $1,09(0,97-1,23)$ \\
\hline Consultório particular & 941 & 34,0 & $0,75(0,67-0,84)$ & $0,98(0,85-1,12)$ \\
\hline Diabetes materno & & & $p=0,3 \#$ & $p=0,1 \#$ \\
\hline Não & 2.440 & 40,3 & 1,00 & 1,00 \\
\hline Sim & 74 & 46,0 & $1,14(0,89-1,47)$ & $1,18(0,95-1,48)$ \\
\hline Infecção do trato urinário na gestação atual & & & $p<0,001 \#$ & $p<0,001 \#$ \\
\hline Não & 1.583 & 33,4 & 1,00 & 1,00 \\
\hline Sim & 925 & 52,1 & $1,56(1,42-1,71)$ & $1,45(1,32-1,59)$ \\
\hline Ganho de peso materno na gestação (kg/quartis) & & & $p=0,7 \#$ & $p=0,3 \#$ \\
\hline Primeiro quartil & 578 & 39,6 & 1,00 & 1,00 \\
\hline Segundo quartil & 624 & 43,0 & $1,08(0,95-1,24)$ & $1,09(0,95-1,24)$ \\
\hline Terceiro quartil & 575 & 41,7 & $1,05(0,92-1,21)$ & $1,14(0,99-1,31)$ \\
\hline Quarto quartil & 500 & 41,2 & $1,04(0,90-1,20)$ & $1,10(0,96-1,27)$ \\
\hline
\end{tabular}

* Ajustado para variáveis do primeiro nível e segundo nível com valor de $\mathrm{p} \leq$ 0,20: cor da pele, idade materna, índice de bens, número de moradores no domicílio, fumo e consumo de álcool materno, prematuridade e corrimento na gestação anterior e realização de citopatológico de colo uterino antes da gravidez;

** Variáveis conservadas no modelo quando o valor de $\mathrm{p}$ foi $\leq 0,20$ na análise ajustada;

*** Teste de Wald de tendência;

\# Teste de Wald de heterogeneidade. 
consultas de pré-natal (43\%), que fizeram prénatal nas unidades básicas de saúde e ambulatórios $(45 \%)$, que se disseram portadoras de diabete mellitus (46\%), que referiram infecção urinária durante a atual gestação (52\%) e que estiveram no segundo quartil de ganho de peso durante a gestação (43\%). Para as demais variáveis, não houve diferença importante na prevalência de corrimento vaginal entre as categorias.

$\mathrm{Na}$ análise ajustada conforme modelo hierárquico previamente definido, as seguintes variáveis perderam a significância estatística: cor da pele, trabalho durante a gravidez, exame citopatológico de colo uterino antes da gestação, número de consultas de pré-natal realizadas, e local de realização do pré-natal. Para a quase totalidade das demais variáveis houve perda de efeito após ajuste para variáveis do mesmo nível e de níveis inferiores. A razão de prevalências (RP) para ocorrência de corrimento vaginal para gestantes adolescentes caiu de 1,57 (1,37-1,80) na análise bruta para $1,53(1,33-1,76)$ na análise ajustada quando comparadas a gestantes com 30 anos ou mais de idade; gestantes com até oito anos de escolaridade apresentaram RP para corrimento vaginal de 1,27 (1,02-1,57) em relação a gestantes com 12 anos ou mais de estudo, enquanto que aquelas pertencentes ao pior tercil de renda familiar apresentavam $\mathrm{RP}=1,16$ $(1,02-1,30)$ em relação àquelas do melhor tercil; gestantes pertencentes ao pior tercil de índice de bens mostraram $\mathrm{RP}=1,20(1,05-1,36)$ e 1,16 $(1,03-1,32)$ de maior ocorrência de corrimento em relação às do melhor tercil; a RP para consumo de álcool materno manteve-se significativamente associada, embora tenha seu efeito reduzido de 1,36 (1,13-1,65) na análise bruta para $1,27(1,04-1,54)$ na analise ajustada; a ocorrência de prematuros em gestação anterior mostrouse protetor à ocorrência de corrimento, tendo passado de $0,85(0,72-1,00)$ na análise bruta para $0,80(0,68-0,95)$ na análise ajustada; o relato de corrimento vaginal em gestação anterior mostrou a maior RP em relação ao corrimento na gestão atual: 1,94 (1,75-2,16), sendo este valor praticamente o mesmo obtido na análise bruta. Por fim, gestantes que relataram ocorrência de infecção do trato urinário na gestação atual também apresentaram maior RP para corrimento vaginal, sendo $1,56(1,42-1,71)$ na análise bruta e $1,45(1,32-1,59)$ na análise ajustada.

\section{Discussão}

O corrimento vaginal referido afetou pelo menos 4 em cada 10 gestantes riograndinas. Sua ocorrência mostrou-se significativamente associada àquelas de menor idade, de pior escolaridade e renda familiar, que consumiram álcool e que referiram infecção do trato urinário na gestação atual e corrimento vaginal patológico na gravidez anterior. O relato de parto prematuro em gestação prévia mostrou-se um fator de proteção à percepção de ocorrência de corrimento vaginal patológico.

Corrimento vaginal é motivo freqüente de consulta médica, sobretudo no período gestacional 1,2. Estudo recente entre gestantes pertencentes à coorte de Pelotas, Rio Grande do Sul, de 2004, revelou prevalência de $47 \%$; outro estudo conduzido com gestantes de baixa renda na periferia da cidade de Rio Grande, em 2005, tendo utilizado o mesmo critério diagnóstico referido neste artigo - presença de corrimento acompanhado de pelo menos prurido, disúria, dispareunia ou odor fétido e coloração que não branca, encontrou prevalência de $52 \%{ }^{8}$. Estas prevalências foram maiores que os $40,3 \%$ aqui encontrados. No caso de Pelotas, esta diferença se deve ao critério diagnóstico utilizado, baseado unicamente no relato de ocorrência de corrimento desde o início da gestação sem a necessidade da presença concomitante de sinais e/ou sintomas. Isto fez com que corrimentos de origem fisiológica fossem, possivelmente, classificados como sendo patológicos. No estudo de Rio Grande foram incluídas somente mulheres de baixo poder aquisitivo (renda familiar mensal inferior a dois salários mínimos mensais) residentes na periferia da cidade, grupo este que sabidamente apresenta maior prevalência deste tipo de patologia 4,5,6,8,10

$\mathrm{O}$ fato de o corrimento vaginal ter mostrado maior razão de prevalência entre adolescentes em relação a gestantes com 30 anos ou mais pode ser atribuído a sua menor imunidade humoral, ao maior número de parceiros sexuais $1,2,3,4,5,12$. Entre as adolescentes, a produção do muco cervical, que funciona como uma espécie de barreira química e mecânica à instalação de processos infecciosos é escassa, o que acaba facilitando a instalação de processos infecciosos 2 . Esta idade é ainda caracterizada não somente por um período de maior atividade sexual, mas também por uma maior rotatividade de parceiros 2,3,4,12. Não fosse a maior taxa de uso de preservativos por parte dos adolescentes, conforme demonstrado recentemente pela Pesquisa de Conhecimentos, Atitudes e Práticas relacionadas à DST/AIDS da População Brasileira em 2008 (PCAP-2008), 
tanto a prevalência de corrimento nesta faixa etária quando suas respectivas RP em relação às demais idades seriam maiores ainda, sobretudo porque o não uso de métodos de barreiras facilita a ocorrência deste tipo de infecção 12,17,18.

A RP para ocorrência de corrimento vaginal entre gestantes com menos de 12 anos de escolaridade e pertencentes ao pior tercil de renda foi de $25 \%$ e $16 \%$ maior em relação àquelas de melhor escolaridade e renda familiar, respectivamente. Outros estudos, também controlando para diversos fatores de confusão, mostram associação neste mesmo sentido, o que evidencia a importância destes fatores na determinação desta doença 4,5,7,8,9,10,11.

A infecção do trato urinário mostrou-se altamente associada ao corrimento vaginal, com $\mathrm{RP}=1,56$ (1,27-1,91). Esta associação foi também encontrada em outros estudos 7,8. A infecção do trato urinário é um dos mais importantes determinantes da prematuridade 19 , sendo os prematuros os que apresentam os maiores riscos de adoecer e morrer no primeiro ano de vida, sobretudo por causas infecciosas 13. Esta associação observada mostra a necessidade do diagnóstico precoce e do manejo adequado do corrimento vaginal a fim de impedir um processo com enorme potencial de ocorrência de óbito infantil.

Neste estudo, o relato de parto prematuro prévio mostrou-se um fator de proteção à percepção da ocorrência de corrimento vaginal, com $\mathrm{RP}=1,37$ (1,04-1,79). Recente meta-análise realizada tendo como desfecho somente as vaginoses bacterianas, que respondem por cerca de metade de todos os corrimentos vaginais patológicos, foi inconclusiva 19. Este achado é inesperado e difícil de interpretar sem fazer diagnóstico da infecção vaginal referida. Há, claramente, necessidade de mais estudos sobre este assunto.

Gestantes que consumiram álcool apresentaram risco significativamente maior à ocorrência de corrimento vaginal $(\mathrm{RP}=1,24 ; 1,04-1,54)$. Identificou-se um único estudo entre gestantes, realizado na Dinamarca, que mostrou associação entre álcool e a ocorrência de vaginose bacteriana 20 .

Finalmente, encontrou-se que o relato de corrimento vaginal em gestação anterior foi o mais importante preditor de corrimento na gestação atual. A RP foi cerca de duas vezes maior $(\mathrm{RP}=1,94 ; 1,75-2,16)$. Embora seja um achado esperado, não se encontrou nenhum outro estudo que tenha avaliado esta associação, mas é plausível pensar que a ocorrência prévia facilite a instalação de novo processo infeccioso ou que, pela presença dos mesmos fatores de risco, o desfecho volte a ocorrer na gestação subseqüente.

Mais recentemente, dois estudos bem conduzidos por Patel et al. 9,10 na Índia mostraram de forma evidente a forte associação entre doença (ou desordem) mental comum, tais como depressão, ansiedade, entre outras, e corrimento vaginal patológico. O risco observado foi de $2,2(1,4-3,2)$. Em vista disso, os autores ressaltam a necessidade de levar em conta aspectos psicossomáticos, em geral, negligenciados durante consulta médica, que contribuem para o estabelecimento de doenças infecciosas como a aqui abordada.

Embora se tenha considerado a combinação de sinais e/ou sintomas para o estabelecimento do diagnóstico de corrimento patológico neste estudo, há que se considerar a possibilidade de superestimativa de prevalência desta doença, visto que se baseia na percepção da gestante. Por exemplo, o aumento da secreção vaginal decorrente da maior transudação e produção de muco cervical, típicos da gravidez, pode estar sendo interpretado como corrimento patológico pela gestante. Não há razão para acreditar que isto tenha ocorrido de forma sistemática e muito menos que fosse capaz de modificar de forma significativa a freqüência desta doença.

O corrimento vaginal de origem patológica mostrou-se altamente prevalente na população estudada, que inclui tanto pacientes atendidos pelo SUS quanto convênio ou particular do Município de Rio Grande. Gestantes de menor idade, escolaridade, pior renda familiar e consumidoras de álcool apresentaram as maiores associações em relação à ocorrência de corrimento vaginal. Especial atenção deveria ser dispensada àquelas com infecção do trato urinário na gravidez atual, que pode ter sido desencadeada por um corrimento patológico subjacente; o mesmo deveria ser feito com gestantes que referiram corrimento em gravidez anterior. Estes foram os principais riscos identificados. Por fim, fica a evidente necessidade de (1) investigar o papel do corrimento vaginal patológico sobre a prematuridade e (2) validar a percepção materna, obtida através de questionários como o utilizado neste estudo, em relação à identificação do agente etiológico responsável por estes corrimentos. 


\section{Resumo}

Este estudo teve por objetivo medir a prevalência e identificar fatores associados à percepção de corrimento vaginal patológico por gestantes residentes em Rio Grande, Rio Grande do Sul, Brasil. Aplicou-se questionário padronizado a todas as parturientes nas maternidades do município em 2007. Utilizou-se teste do qui-quadrado para comparar proporções e análise multivariável por regressão de Poisson. A prevalência de corrimento vaginal foi de $40 \%$. Análise ajustada mostrou as seguintes razões de prevalência: 1,6 (1,41,8) para adolescentes; 1,3 (1,1-1,6) para aquelas com até oito anos de escolaridade; 1,3 (1,1-1,5) para aquelas que ingeriram álcool; 2,0 (1,8-2,2) para aquelas que referiram corrimento vaginal em gestação anterior; 1,4 (1,3-1,6) para infecção urinária na gestação atual; prematuridade em gestação anterior mostrouse protetor com $R P=0,8(0,7-0,9)$. Os serviços de saúde deveriam priorizar diagnóstico e tratamento de corrimento vaginal entre gestantes adolescentes, de baixa renda familiar e escolaridade, com história prévia de corrimento em gravidez anterior e infecção urinária na gravidez atual.

Corrimento Vaginal; Vaginite; Gestantes

\section{Colaboradores}

J. A. Cesar elaborou o projeto e realizou a análise de dados e a redação final do artigo. R. A. Mendoza-Sassi contribuiu com a elaboração do projeto, análise de dados e redação final do artigo. D. A. González-Chica auxiliou na análise dos dados e redação do artigo. E. H. M. Menezes, G. Brink, M. Pohlmann e T. M. V. Fonseca auxiliaram na preparação de instrumento, coleta de dados e redação final do artigo.

\section{Agradecimentos}

À Fundação de Amparo à Pesquisa do Rio Grande do Sul (FAPERGS), Pastoral da Criança e Secretaria de Saúde e Ação Social da Prefeitura Municipal de Rio Grande.

\section{Referências}

1. Naud P, Matos JC, Hammes LS, Magno V. Secreção vaginal e prurido vulvar. In: Duncan BB, Schmidt MI, Giugliani EJ, organizadores. Medicina ambulatorial: condutas de atenção primária baseada em evidências. 3a Ed. Porto Alegre: Editora Artmed; 2004. p. 460-4.

2. Amaral ALP, Oliveira HC, Amaral LFP, Oliveira MAP. Corrimento genital. In: Halbe HW, organizador. Tratado de ginecologia. 2a Ed. São Paulo: Editora Roca; 1994. p. 501-11.

3. Programa Nacional de DST e AIDS, Secretaria de Vigilância em Saúde, Ministério da Saúde. Manual de controle doenças sexualmente transmissíveis. 4ạ Ed. Brasília: Ministério da Saúde; 2006. (Séries Manuais, 68)

4. Mullick S, Watson-Jones D, Beksinska M, Mabey D. Sexually transmitted infections in pregnancy: prevalence, impact on pregnancy outcomes, and approach to treatment in developing countries. Sex Transm Infect 2005; 81:294-302.
5. Nicolai LM, Ethier KA, Kathleen A, Kershaw TS, Lewis JB, Ickovics JR. Pregnant adolescents at risk: sexual behaviors and sexually transmitted disease prevalence. Am J Obstet Gynecol 2003; 188:63-70.

6. Barney OJ, Natahan M. A study of the prevalence of sexually transmitted infections and related conditions in pregnant women attending a sexual health service. Int J STD AIDS 2005; 16:353-6.

7. Larsson PG, Fåhraeus L, Carlsson B, Jakobsson T, Forsum U. Predisposing factors for bacterial vaginosis, treatment efficacy and pregnancy outcome among term deliveries; results from a preterm delivery study. BMC Womens Health 2007; 7:20.

8. Fonseca TMV, Cesar JA, Hackenhaar AA, Ulmi EF, Neumann NA. Corrimento vaginal referido entre gestantes em localidade urbana no Sul do Brasil: prevalência e fatores associados. Cad Saúde Pública $2008 ; 24: 558-66$ 
9. Patel V, Pednekar S, Weiss H, Rodrigues M, Barros P, Nayak B, et al. Why do women complain of vaginal discharge? A population survey of infectious and psychosocial risk factors in a South Asian community. Int J Epidemiol 2005; 34:853-62.

10. Patel V, Weiss HA, Kirkwood BR, Pednekar S, Nevrekar P, Gupte S, et al. Common genital complaints in women: the contribution of psychosocial and infectious factors in a population-based cohort study in Goa, India. Int J Epidemiol 2006; 35:1478-85.

11. Jacobson B, Pernevi P, Chidekel L, Platz-Christensen JJ. Bacterial vaginosis in early pregnancy may predispose for preterm birth and postpartum endometritis. Acta Obstet Gynecol Scand 2002; 81:1006-10.

12. Department of Reproductive Health and Research, World Health Organization. Guidelines for the management of sexually transmitted infections. http://www.who.int/reproductivehealth/publica tions/rtis/9241546263/en/index.html (acessado em 14/Ago/2005).

13. Victora CG, Barros FC, Vaughan JP. Epidemiologia da desigualdade: um estudo longitudinal de 6.000 crianças brasileiras. 2a Ed. São Paulo: Editora Hucitec; 1988.

14. Suhr DD. Principal component analysis vs. exploratory factor analysis. http://www2.sas.com/ proceedings/sugi30/203-30.pdf (acessado em 14/ Mai/2009).
15. Victora CG, Huttly SR, Fuchs SC, Olinto MT. The role of conceptual frameworks in epidemiological analysis: a hierarchical approach. Int J Epidemiol 1997; 26:224-7.

16. Kirkwood BR, Sterne J. Essentials of medical statistics. 2nd Ed. London: Blackwell Science; 2003.

17. Fonck K, Kidula N, Jaoko W, Estambale B, Claeys $\mathrm{P}$ Ndinya-Achola J, et al. Validity of the vaginal discharge algorithm among pregnant women and non-pregnant women in Nairobi, Kenya. Sex Transm Infect 2000; 76:33-8.

18. Programa Nacional de DST e AIDS, Secretaria de Vigilância em Saúde, Ministério da Saúde. Pesquisa de conhecimentos, atitudes e práticas relacionada às DST e AIDS da população brasileira de 15 a 64 anos de idade (PCAP-2008). http://www.aids.gov.br/data/documents/ storedDocuments/\%7BB8EF5DAF-23AE-4891AD36-1903553A3174\%7D/\%7BFB7ECC9A-CDF1440E-AF64-53CE1C5BAE6B\%7D/PCAP-BR\%20 CNAIDS.ppt (acessado em 24/Ago/2009).

19. Cram LF, Zapata MI, Toy EC, Baker B. Genitourinary infections and their association with preterm labor. Am Fam Physician 2002; 65:241-8.

20. Thorsen P, Vogel I, Molsted K, Jacobsson B, Arpi M, Møller BR, et al. Risk factors for bacterial vaginosis in pregnancy: a population-based study on Danish women. Acta Obstet Gynecol Scand 2006; 85: 906-11.

Recebido em 27/Mai/2009

Versão final reapresentada em 27/Ago/2009

Aprovado em 09/Set/2009 